\title{
Fine fibrillar and rectangular/hexagonal ordered grains of poly (3-hexyl thiophene) and poly(ethylene glycol) developed by seeding technique
}

\author{
S. Agbolaghi ${ }^{1,2} \cdot$ M. Alizadeh-Osgouei ${ }^{1,2} \cdot$ S. Zenoozi ${ }^{1,2} \cdot$ S. Abbaspoor ${ }^{1,2}$. \\ F. Abbasi ${ }^{1,2}$
}

Received: 17 September 2016/ Accepted: 4 November 2016/Published online: 16 November 2016

(C) The Author(s) 2016. This article is published with open access at Springerlink.com

\begin{abstract}
The fibrillar poly(3-hexyl thiophene) single crystals were prepared from dilute solutions of toluene, xylene, and anisole $(0.01 \mathrm{wt} \%)$, and were investigated from the perspective of structural properties. Next, the rectangular and hexagonal poly(ethylene glycol) single crystals were developed from the dilute solutions and molten thin polymer films. The developing methodology used for all growth systems was self-seeding. The dimensions of fibrillar and rectangular/hexagonal single crystals ranged from several nanometers to some microns. Random single-co-crystals were also grown from dilute solution (0.018 wt \% in amyl acetate) of crystalline-amorphous diblock copolymers and homopolymers. The small-angle $\mathrm{X}$-ray scattering, grazing incidence wide-angle X-ray scattering, and atomic force microscopy analyses were employed to characterize prepared grained samples. The incident X-ray experiments demonstrated highly ordered and lamellar crystalline structures.
\end{abstract}

Keywords P3HT · Single crystal · PEG · Self-seeding · Single-co-crystal

S. Agbolaghi

s_agbolaghi@sut.ac.ir

1 Institute of Polymeric Materials, Sahand University of Technology, Tabriz, Iran

2 Faculty of Polymer Engineering, Sahand University of Technology, Tabriz, Iran

\section{Introduction}

Crystallization significantly changes the physical and mechanical features of polymer systems. Even though in crystallization state different morphologies are obtainable from concentrated solutions or from polymer melts, ranging from axialites, dendrites to spherulites, crystallization into somehow well-defined single crystals is delimited to supercooled dilute solutions [1]. An ample range of empirical works were dedicated to study the diffraction effects, lateral habits, lamellar structures, and crystal orientation of poly(ethylene oxide) (PEO) single crystals [1-13]. In a frontier step, Lin and his coworker studied semicrystalline diblock copolymer platelets of PEO- $b$ polystyrene (PS) in dilute solution by means of small-angle neutron scattering (SANS) [14]. Scanning force microscopy (SFM) images of the surfaces of PEO crystals revealed oriented fibril-like growth with increasing annealing temperature [15]. Recently, polymer single crystals and highly ordered structures have been employed in distinct potential applications including programmable assembly of nanoparticles [16], mimicking the natural bone nanostructures [17], magnetically recyclable catalyst support [18-22], templates to synthesize nanoparticle clusters [23, 24], substrates for anisotropic deposition of $\mathrm{Au}$ nanoparticles [25], utilizable in semiconductor microelectronics and solid-state [26, 27], ultrathin film systems [28], delivery systems for human papilloma virus-associated tumors [29-31], nano/micromotors [32, 33], and photovoltaic devices [34].

In the realm of semiconductive polymers, large single rectangular crystals of 3-hexyl thiophene $(3 \mathrm{HT})_{8}[35,36]$, nanowires of conjugated poly( $p$-phenylene ethynylene) derivatives [37], poly(3-hexyl thiophene) (P3HT) nanowhiskers [38], one-dimensional (1D) microwire P3HT 
single crystals [39], and self-organized two-dimensional (2D) P3HT supramolecules [40, 41] were reported. Nascent lateral habits of solution-grown single crystals [42], surface-patterned single crystals [43-47], and conductive-dielectric-conductive single crystals [48-50] have also been reported.

The current work with the objective of comparing the features of crystalline structures for semiconductive rigid and dielectric coily polymers was divided into three distinct sections. First, the fibrillar P3HT semiconductive single crystals were developed from three different solvents, i.e., toluene, xylene, and anisole using the selfseeding method. Second, the dielectric rectangular poly(ethylene glycol) (PEG) single crystals were grown by the same methodology but from amyl acetate. Afterward, the hexagonal melt-grown PEG single crystals were prepared from thin polymer films, and their growth prisms and lateral habit were compared with the corresponding solutiongrown PEG single crystals. Third, the effect of amorphous blocks on the thickness of crystalline substrate was investigated through growing the single-co-crystals of PEG- $b$ PS/PEG and PEG- $b$-poly(methyl methacrylate) (PMMA)/ PEG. The novelty of this work was constructing the highquality fibrillar P3HT single crystals using the self-seeding procedure, and also comparing the structural characteristics of semiconductive single crystals with the dielectric single crystals.

\section{Experimental}

\section{Methods}

Highly regioregular P3HTs (>99\%) with different molecular weights $\left(M_{n}^{\mathrm{P} 3 \mathrm{HT}}\right)$ and the polydispersity index (PDI) of 1.21-1.25 were synthesized using Grignard metathesis polymerization [51]. Diblock copolymers of PEG- $b$-PS and PEG- $b$-PMMA having various molecular weights of PS and PMMA blocks were synthesized via solution polymerization in chlorobenzene (CB, Merck, >99\%) by ATRP. Detailed synthesis procedures were described elsewhere [42, 43].

\section{Single crystal growth}

The P3HT single crystals were grown in toluene (best solvent), xylene (intermediate solvent), and anisole (poorest solvent) by the self-seeding method with the concentration of $0.01 \mathrm{wt} \%$. The single crystals were grown at different seeding temperatures $\left(T_{\mathrm{s}}\right)$ and crystallization temperatures $\left(T_{\mathrm{c}}\right)$. First, the prepared samples were heated for $30 \mathrm{~min}$ at $75{ }^{\circ} \mathrm{C}$ in toluene, at $85{ }^{\circ} \mathrm{C}$ in xylene, and at $95{ }^{\circ} \mathrm{C}$ in anisole. The vials were then kept at $0{ }^{\circ} \mathrm{C}$ overnight for fast primary crystallization. The seeding step was conducted for $3 \mathrm{~min}$ at respective $T_{\mathrm{s}}$ and, subsequently, the samples were kept at the secondary crystallization temperature $\left(T_{\mathrm{c}}\right)$ for 3 days to complete the crystal growth. In more details, in the primary crystallization step, the non-ideal crystals (not single crystals) were prepared. These crystals were dissolved in the self-seeding step leading to highly populated tiny seeds. During the secondary crystallization step, the crystallizable chains attached to these seeds remained from the self-seeding step to fabricate the ultimate large single crystals.

Polyethylene glycol monomethyl ether 5000 (PEG) (Aldrich) with narrow molecular weight distribution $(\mathrm{PDI}=1.06)$ was employed to grow single crystals. The self-seeding technique was applied for growing single crystals. Solution crystallization was carried out with a dilute concentration of $0.008 \mathrm{wt} \%$ in amyl acetate as solvent, and melt crystallization was conducted without solvent and on appropriate silicon wafers. The sample was heated to above the dissolution temperature $\left(T_{\mathrm{d}}=42{ }^{\circ} \mathrm{C}\right)$ in solution system and melting temperature in bulk system $\left(T_{\mathrm{m}}=65^{\circ} \mathrm{C}\right)$ in a temperature-controllable oil bath for $15 \mathrm{~min}$. Then it was transferred to a $0^{\circ} \mathrm{C}$ bath lasting $5 \mathrm{~h}$ for fast crystallization and, subsequently, immersed into a given self-seeding temperature oil bath, and kept for 20 min. The sample was then quickly switched into a desired isothermal oil bath adjusted at crystallization temperature, and maintained for 2 days. Self-seeding method was also used to grow the single-co-crystals. Solution single crystallization was carried out in amyl acetate (Merck, >98\%). Desired amount of solutes (50/50 $\mathrm{wt} / \mathrm{wt}$ of homo and copolymer) and amyl acetate were added into the cell tube to reach the dilute concentration of $0.018 \mathrm{wt} \%$. Then the sealed cell tube was heated to above the dissolution temperature $\left(T_{\mathrm{d}}=65^{\circ} \mathrm{C}\right)$ in a temperaturecontrollable oil bath, and kept for about $12 \mathrm{~min}$. Then cell tube was switched to another oil bath at present $-10{ }^{\circ} \mathrm{C}$ lasting $5 \mathrm{~h}$ for crystallization. The cell tube was then immersed into a given self-seeding temperature $\left(T_{\mathrm{s}}\right)$ oil bath $\left(T_{\mathrm{s}}=41{ }^{\circ} \mathrm{C}\right)$, and kept for $15 \mathrm{~min}$. The cell tube was then quickly transferred into an isothermal oil bath preset at a given crystallization temperature $\left(T_{\mathrm{c}}\right)$, and maintained for 2-3 days.

\section{Results and discussion}

\section{Fibrillar semiconductive P3HT single crystals}

Use of the self-seeding method led to completely uniform population in the semiconductive fibrillar P3HT single crystals. Figure 1a, b illustrates atomic force microscopy (AFM) height image of $\mathrm{P}_{3} \mathrm{HT}_{48800}$ single crystals grown 

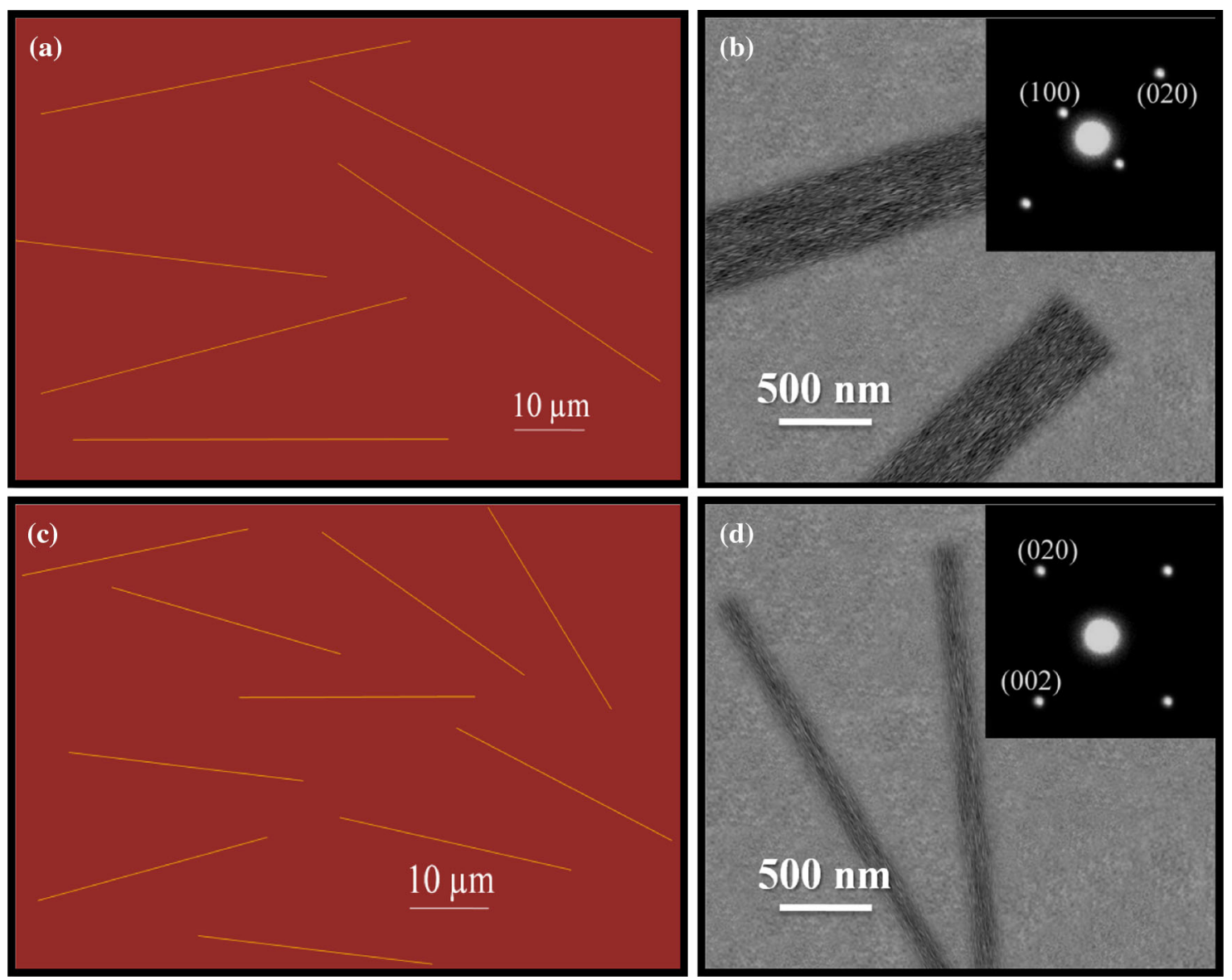

Fig. 1 AFM height image (a) and TEM image accompanied by the corresponding SAED pattern in the inset (b) for $\mathrm{P}_{3} \mathrm{HT}_{48800}$ single crystals grown from xylene at $T_{\mathrm{s}}=40{ }^{\circ} \mathrm{C}, T_{\mathrm{c}}=30{ }^{\circ} \mathrm{C}$; AFM height

from xylene at $T_{\mathrm{s}}=40{ }^{\circ} \mathrm{C}, T_{\mathrm{c}}=30{ }^{\circ} \mathrm{C}$ and TEM image accompanied by the corresponding selected area electron diffraction (SAED) pattern. The dimensions of these single crystals in the $a$ [thickness of single crystal or hexyl side chains or (100) direction], $b$ [length of single crystal or $\pi-\pi$ stacking or (020) direction], and $c$ (width of single crystal or longitude of P3HT main backbones) axes were $437.50 \mathrm{~nm}, 64.55 \mu \mathrm{m}$, and $116.87 \mathrm{~nm}$, respectively. In the SAED patterns of Fig. 1b, two pairs of (100) prisms in the $a$-axis or the hexyl side chains direction and two pairs of (020) prisms in the $b$-axis or the $\pi-\pi$ stacking direction demonstrated a flat-on orientation for the P3HT chains, in which the main backbones and the hexyl side chains were perpendicular and parallel to the substrate, respectively. The schemes of Fig. 2 depict the folded flat-on (top, right) and laminated flat-on (bottom, right) P3HT chains for the high molecular weight $(48,000 \mathrm{~g} / \mathrm{mol})$ and low molecular weight $(21,000$ and $7150 \mathrm{~g} / \mathrm{mol})$ P3HTs, respectively. Likewise, AFM height image of $\mathrm{P}_{3} \mathrm{HT}_{21000}$ single crystals grown from toluene at $T_{\mathrm{s}}=30{ }^{\circ} \mathrm{C}, T_{\mathrm{c}}=20^{\circ} \mathrm{C}$ and TEM image with the corresponding SAED pattern in the inset are image (c) and TEM image accompanied by the corresponding SAED pattern in the inset (d) for $\mathrm{P}_{3} \mathrm{HT}_{21000}$ single crystals grown from toluene at $T_{\mathrm{s}}=30{ }^{\circ} \mathrm{C}, T_{\mathrm{c}}=20^{\circ} \mathrm{C}$

represented in Fig. 1c, d. The similarity from the perspectives of thickness, width, and length of fibrillar single crystals was detected in this growth system as well. The dimensions of these single crystals in the $a, b$, and $c$ directions were $95.00 \mathrm{~nm}, 36.75 \mu \mathrm{m}$, and $100.55 \mathrm{~nm}$, respectively. In the SAED pattern of the fibrillar P3HT single crystals depicted in Fig. 1d, (020) prisms in the $\pi-\pi$ stacking direction and (002) in the longitude of P3HT backbone were detected. This pattern was indicative of an edge-on orientation, in which the P3HT main backbones and the hexyl side chains were parallel with and perpendicular to the substrate, respectively. The schemes of Fig. 2 represent the folded edge-on (top, left) and laminated edgeon (bottom, left) P3HT chains for the high molecular weight $(48,000 \mathrm{~g} / \mathrm{mol})$ and low molecular weight $(21,000$ and $7150 \mathrm{~g} / \mathrm{mol}$ ) P3HTs, respectively.

Furthermore, as shown in the two-dimensional grazing incidence wide-angle $\mathrm{X}$-ray scattering (2D-GIWAXS) plots of Fig. 3a-c, the (100) growth planes (hexyl side chains direction) and (020) growth planes ( $\pi-\pi$ stacking direction) appeared in out of plane (OOP) and in plane (IP) 


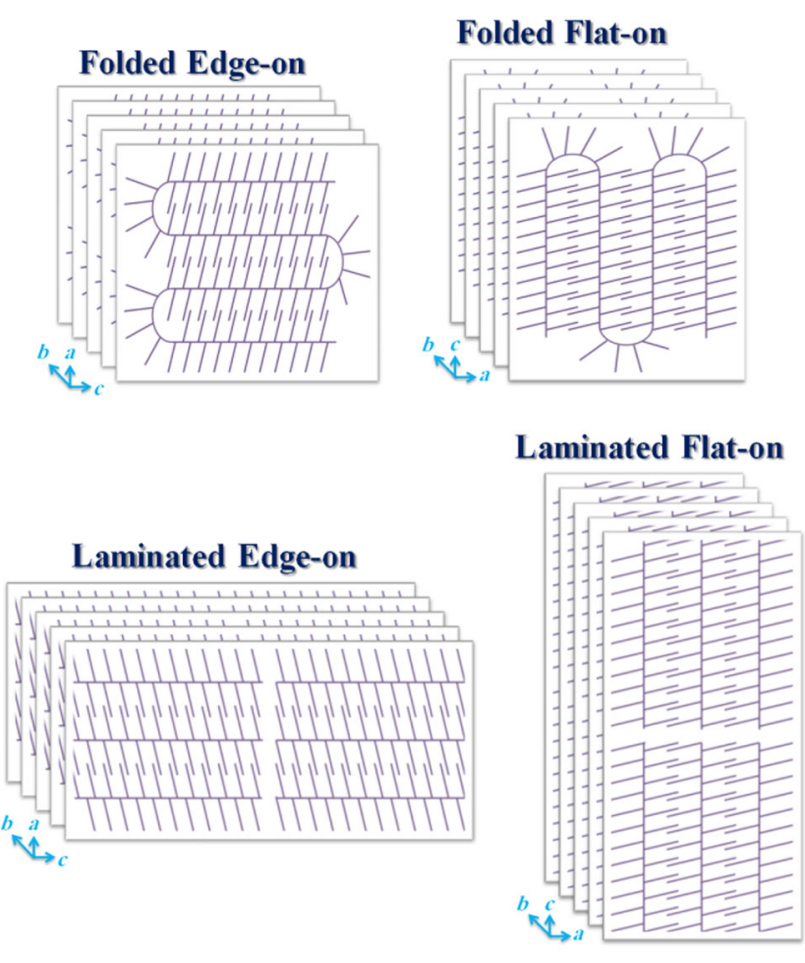

Fig. 2 Scheme of backbone folding in high molecular weight P3HTs in edge-on-oriented (top, left) and flat-on-oriented (top, right) single crystals as well as backbone lamination in low molecular weight P3HTs in edge-on-oriented (bottom, left) and flat-on-oriented (bottom, right) single crystals axes, respectively. In different parts of Fig. 3, the 2D GIWAXS plots of $\mathrm{P} 3 \mathrm{HT}_{7150}$ single crystals grown from toluene $\left(T_{\mathrm{s}}=20{ }^{\circ} \mathrm{C}, T_{\mathrm{c}}=0{ }^{\circ} \mathrm{C}\right)$, xylene $\left(T_{\mathrm{s}}=40{ }^{\circ} \mathrm{C}\right.$, $\left.T_{\mathrm{c}}=10{ }^{\circ} \mathrm{C}\right)$, and anisole $\left(T_{\mathrm{s}}=50{ }^{\circ} \mathrm{C}, T_{\mathrm{c}}=40{ }^{\circ} \mathrm{C}\right)$ are reported.

In the investigated growth systems, the P3HT chains with the lower molecular weights $(=7150$ and 21,000 g/mol) depicted backbone laminating states; however, those with $M_{n}^{\mathrm{P} 3 \mathrm{HT}}$ of $48,800 \mathrm{~g} / \mathrm{mol}$ were folded in the $c$-direction. The folding numbers for the homopolymer single crystals were obtained by dividing the P3HT extended length to the width of single crystals (i.e., $\mathrm{D}_{(002)}$ dimension detected from width of AFM height profiles). In a similar growth condition, better solvents induced a higher number of foldings. The folding number mostly reduced parallel with $T_{\mathrm{c}}$ enhancement. In toluene at $T_{\mathrm{s}}=30^{\circ} \mathrm{C}$, by increasing $T_{\mathrm{c}}$ from 0 to 10 and $20{ }^{\circ} \mathrm{C}$, the foldings in $\mathrm{P}_{3} \mathrm{HT}_{48800}$ single crystals changed from 3 to 2 and finally 1. The maximum P3HT backbone lamination of 60 occurred in $\mathrm{P}_{3} \mathrm{HT}_{7150}$ single crystals grown from anisole (the weakest utilized solvent in this work) at $T_{\mathrm{s}}=60{ }^{\circ} \mathrm{C}$ and $T_{\mathrm{c}}=20{ }^{\circ} \mathrm{C}$. By increasing $M_{n}^{\mathrm{P} 3 \mathrm{HT}}$ from 7150 to 21 $000 \mathrm{~g} / \mathrm{mol}$, a fewer numbers of the P3HT backbones were laminated. With enhancing the crystallization temperature, the driving force for backbone laminating decreased for homopolymer single crystals. In $\mathrm{P}_{3} \mathrm{HT}_{7150}$ single crystals (a)

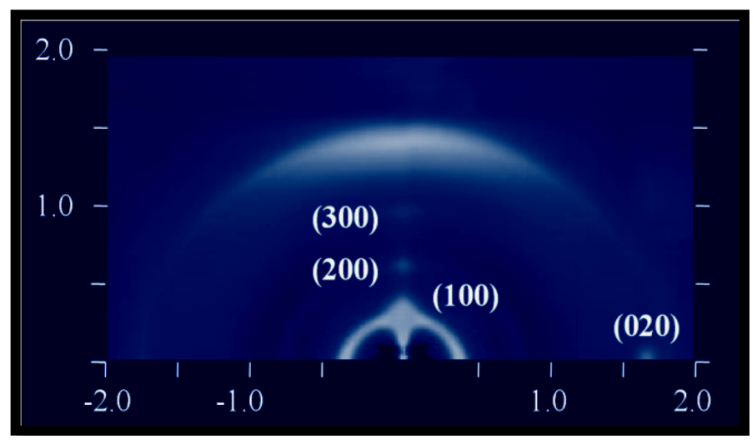

(b)

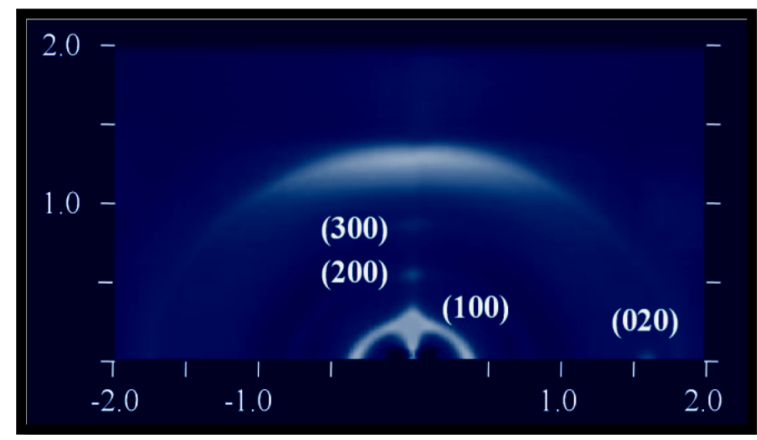

(c)

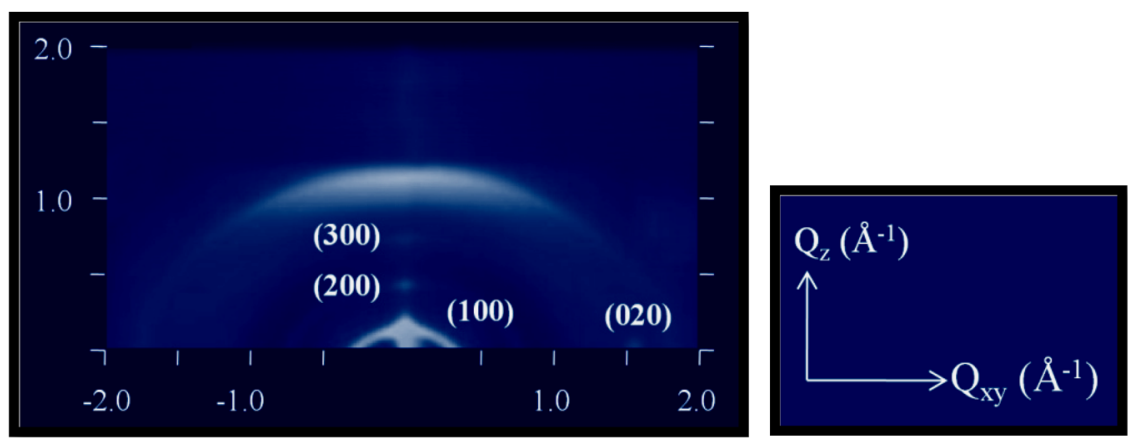

Fig. 3 The 2D GIWAXS plots of $\mathrm{P} \mathrm{HT}_{7150}$ single crystals grown from toluene at $T_{\mathrm{s}}=20{ }^{\circ} \mathrm{C}, T_{\mathrm{c}}=0{ }^{\circ} \mathrm{C}(\mathbf{a}), \mathrm{xylene}$ at $T_{\mathrm{s}}=40{ }^{\circ} \mathrm{C}, T_{\mathrm{c}}=10{ }^{\circ} \mathrm{C}$ (b), and anisole at $T_{\mathrm{s}}=50{ }^{\circ} \mathrm{C}, T_{\mathrm{c}}=40{ }^{\circ} \mathrm{C}$ (c) 
grown from xylene at $T_{\mathrm{s}}=40^{\circ} \mathrm{C}$, through altering $T_{\mathrm{c}}$ from 10 to 20 and $30{ }^{\circ} \mathrm{C}$, the backbone laminating numbers were equal to 25,22 , and 18 , respectively. The weaker solvents caused $\mathrm{P}_{3} \mathrm{HT}_{7150}$ and $\mathrm{P} 3 \mathrm{HT}_{21000}$ chains to have more backbone laminations. In $\mathrm{P}_{3} \mathrm{HT}_{7150}$ single crystals grown at $T_{\mathrm{s}}=30{ }^{\circ} \mathrm{C}$ and $T_{\mathrm{c}}=10{ }^{\circ} \mathrm{C}$, the laminating numbers in toluene and xylene were 6 and 25, respectively. By increasing the molecular weight of P3HT block from 7150 to $21,000 \mathrm{~g} / \mathrm{mol}$ in a similar growth condition, the laminating numbers changed to 3 and 10 in toluene and xylene, respectively.

By increasing the molecular weight of P3HT, the growth of single crystal occurred slowly in the $a$-direction. In anisole at $T_{\mathrm{s}}=50{ }^{\circ} \mathrm{C}$ and $T_{\mathrm{c}}=20{ }^{\circ} \mathrm{C}$, the thicknesses of $\mathrm{P}_{3} \mathrm{HT}_{7150}$ and $\mathrm{P}_{3} \mathrm{HT}_{21000}$ single crystals were 1180.22 and $1130.14 \mathrm{~nm}$, respectively. The poorer solvent resulted in thicker fibrillar single crystals. The thicknesses of fibrillar $\mathrm{P}_{3} \mathrm{HT}_{21000}$ single crystals in toluene and xylene were 95.00 and $401.00 \mathrm{~nm}$, respectively. The elevated crystallization temperatures due to providing a lower driving force for stacking of the P3HT chains in the hexyl chains direction led to thinner fibrils. In xylene at $T_{\mathrm{s}}=30{ }^{\circ} \mathrm{C}$, the thicknesses of $\mathrm{P}_{3} \mathrm{HT}_{48800}$ single crystals grown at the crystallization temperatures of 10 and $20{ }^{\circ} \mathrm{C}$ were 404.56 and $365.70 \mathrm{~nm}$, respectively. The stacking also increased in $\pi-$ $\pi$ direction using the poorer solvents. At $T_{\mathrm{s}}=30{ }^{\circ} \mathrm{C}$ and at $T_{\mathrm{c}}=10^{\circ} \mathrm{C}$, the lengths of $\mathrm{P} \mathrm{HT}_{48800}$ single crystals were 34.85 and $54.02 \mu \mathrm{m}$ in toluene and xylene, respectively. Via $M_{n}^{\mathrm{P} 3 \mathrm{HT}}$ increase, $\pi-\pi$ stacking was weakened in the fibrillar single crystals. In xylene at $T_{\mathrm{s}}=30^{\circ} \mathrm{C}$, the lengths of $\mathrm{P}_{3} \mathrm{HT}_{7150}, \mathrm{P}_{3} \mathrm{HT}_{21000}$, and $\mathrm{P}_{3} \mathrm{HT}_{4880}$ single crystals were $59.75,56.79$, and $53.89 \mu \mathrm{m}$, respectively.

\section{Rectangular/hexagonal dielectric PEG single crystals}

The PEG single crystals developed from dilute solution were rectangular; however, the corresponding single crystals grown from melt state were hexagonal. It could be ascribed to the regular prism faces which are (120) and (140) for solution- and melt-grown single crystals, respectively. In general, the growth conditions led to the appearance of growth prisms with different growth rates. By competing with the growth planes having different rates, the prisms with the lower growth rates dictated the ultimate lateral habit or shape of developed single crystals. The seeds acquired from the self-seeding step were also analyzed. In either solution or melt circumstance, the size of seeds ranged $0.5-1 \mathrm{~nm}$. The shape of seeds was similar and cubic-like in solution and melt states. Therefore, this was not the type or shape of added seeds which determined the final lateral habits of grown single crystals. The subsequent growth condition such as the concentration governed the lateral habits and lateral sizes.

AFM height images of homo- PEG $_{5000}$ single crystals grown from amyl acetate and molten thin film at $T_{\mathrm{c}}=28{ }^{\circ} \mathrm{C}$ accompanied by the SAED patterns and AFM height profiles are illustrated in Fig. 4a, b. The thickness of the hexagonal single crystal grown from melt was $16.3 \mathrm{~nm}$ while that of solution-grown one was $11.1 \mathrm{~nm}$. This difference was also detected for the lateral sizes. The lateral size of melt-grown single crystals was $24.5 \mu \mathrm{m}$; however, that of solution-grown one was $6.5 \mu \mathrm{m}$. Generally, the feasible prism fronts for a PEG single crystal was categorized as (110), (120), (140), (100), (200), (010), (020), and (040) [42]. As mentioned above, in lamellar growth of single crystal, different prism fronts are in competition with each other, and those that have lower rate could form the determinant faces because from a kinetic point of view, lower rate is a controlling factor. The dilution of system as well as strength of interactions before being included in the crystalline structure could in turn affect the growth fronts. Furthermore, both solution-grown and melt-grown single crystals demonstrated a flat-on orientation, in which the lamellar PEG backbones were perpendicular to the substrate (Fig. 5), via two symmetric pairs of (120) and (140) spots in electron diffraction patterns.

Totally, as mentioned in the previous section, when the comb-like conjugated backbones such as P3HT assembled to construct an ordered crystalline structure, two different types of stackings comprising $\pi-\pi$ stacking in the longitude of fibrillar crystals or in the (020) axis and also the hexyl side chains stacking in the thickness of fibrils or in the (100) axis occurred. Based on dimensions of fibrillar single crystals in the $a, b$, and $c$ directions, the edge-on and flat-on orientations were detected. On the other side, for the PEG lamellar single crystals usually a flat-on orientation with (120) prisms in dilute solution state and (100) and (140) prisms in the melt state was detected. Moreover, the conjugated $\mathrm{P} 3 \mathrm{TH}$ chains because of having a rigid nature had a tendency to possess the backbone foldings in the higher molecular weights, here $48800 \mathrm{~g} / \mathrm{mol}$, compared to the coily PEG backbones. Actually, the PEG blocks were capable of folding even in very low molecular weights, i.e., $5000 \mathrm{~g} / \mathrm{mol}$. In contrast, the P3HT backbones up to $21,000 \mathrm{~g} / \mathrm{mol}$ were laminated on each other (Fig. 2 bottom), and chain folding was only detected for P3HTs having the molecular weight of $48,800 \mathrm{~g} / \mathrm{mol}$ (Fig. 2 top).

The 2D small-angle X-ray scattering (SAXS) pattern in Fig. $6 \mathrm{a}$ is indicative of two sorts of scattering which are dense polymers such as discrete interferences and diffuse central section. The diffuse scattering may originate from the micro-voids of the sample. The micro-voids are unfilled spaces between the lamellae [52, 53]. Discrete 
Fig. 4 TEM image (top) and the corresponding ED pattern in the inset as well as AFM height image (bottom, left) and height profile (bottom, right) of homo$\mathrm{PEG}_{5000}$ single crystals at $T_{\mathrm{c}}=28^{\circ} \mathrm{C} ;$ a solution state (amyl acetate), thickness: $11.1 \mathrm{~nm}$ and lateral size: $6.5 \mu \mathrm{m}$; b melt state, thickness: $16.3 \mathrm{~nm}$ and lateral size: $24.5 \mu \mathrm{m}$ (a)
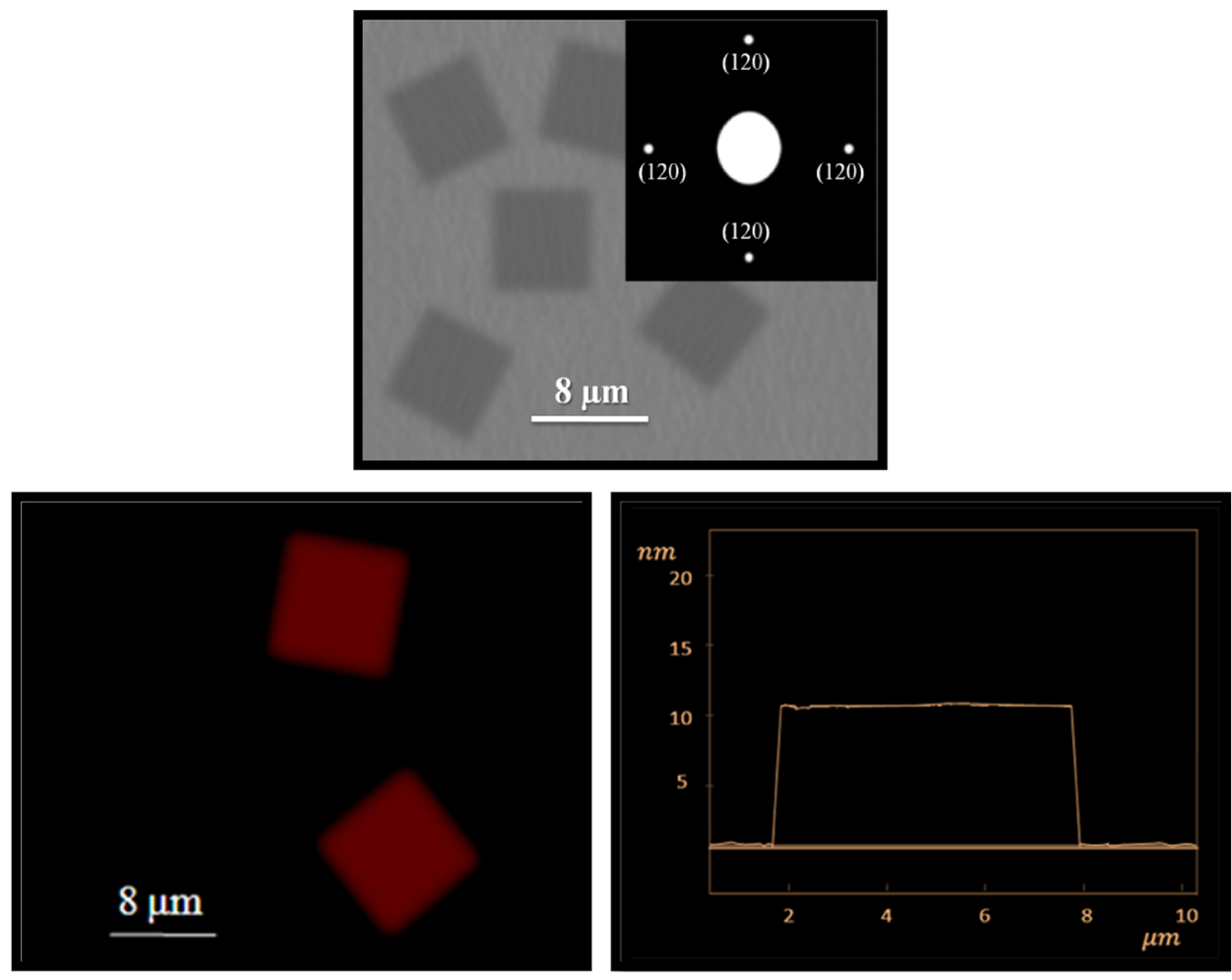

(b)
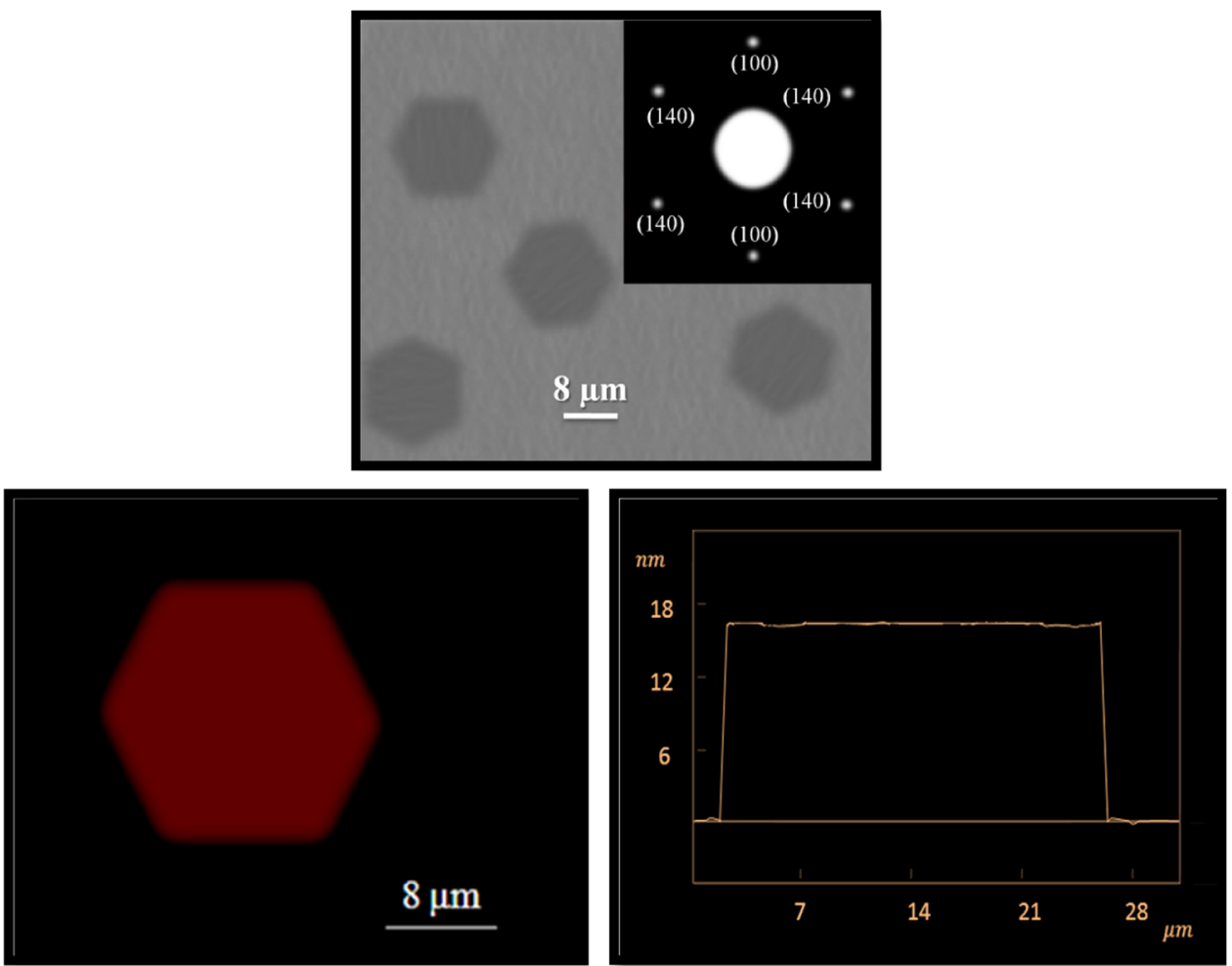

interferences are shown on the meridian of the 2D SAXS pattern. A periodic structure could be inferred from orders of the main interference maximum. A typical measurement performed on single crystal mat of homo-PEG S000 $_{\text {devel- }}$ oped at $28{ }^{\circ} \mathrm{C}$ is given in Fig. 6b. In 2D SAXS pattern, the scattering intensity was concentrated in the equatorial 
Folded Flat-on

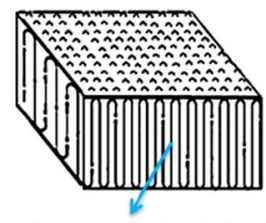

Crystalline Lamellar PEG Substrate
Further Folded Flat-on

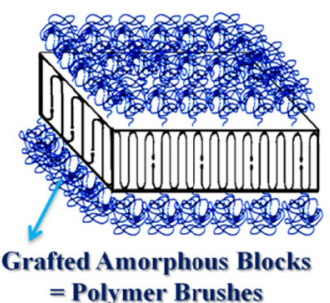

= Polymer Brushes

Fig. 5 Schematic representation of lamellar PEG single crystals prepared by homo-PEG and PEG block copolymers attached to a coily amorphous chain

plane, and it depicted at least three orders of the interference maximum proving good ordering within the single crystal stacks. In the ideal case of stacked parallel platelets, the pattern should contain only a series of equatorial spots.

Figure 6c shows 1D correlation function $(\gamma)$ presenting the micro-structural parameters. This graph represented that the sample had an ideal lamellar morphology as shown in Fig. 5. First flat minimum of 1D correlation function was used to determine the value of crystallinity $\left(\Phi_{\mathrm{L}}\right)$. The long period or thickness referred as the Bragg peak was predicted from the position of the first maximum of 1D correlation function $(\gamma)$. The $\gamma_{\min }$ was related to the crystallinity, $\Phi_{\mathrm{L}}$, as followed by Eq. (1) [54].

$\gamma_{\min }=\frac{1-\Phi_{L}}{-\Phi_{L}} \quad$ for $\Phi_{L}>0.5$

Here, $\gamma_{\min }=-0.05$; so, $\Phi_{\mathrm{L}}=0.95$ or $95 \%$. The AFM height profiles and SAXS 1D correlation functions had a high consistency with each other. For homo-PEG ${ }_{5000}$ single crystals grown from melt state, the average thickness from AFM height profile (Fig. 4b) and SAXS 1D correlation functions (Fig. 6c) was equal to 16.3 and $16.9 \mathrm{~nm}$, respectively.

(a)

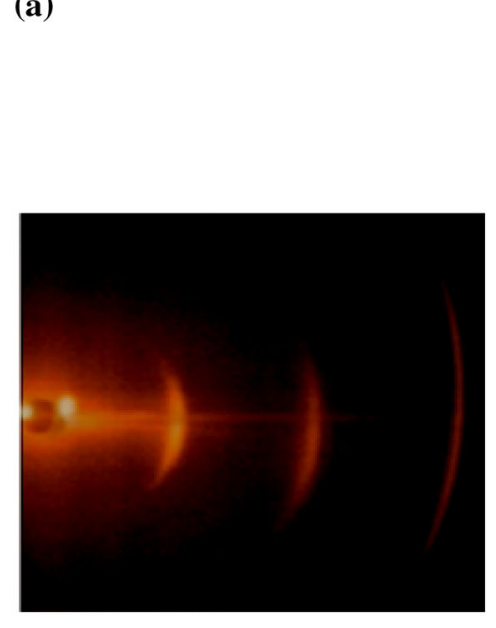

(b)

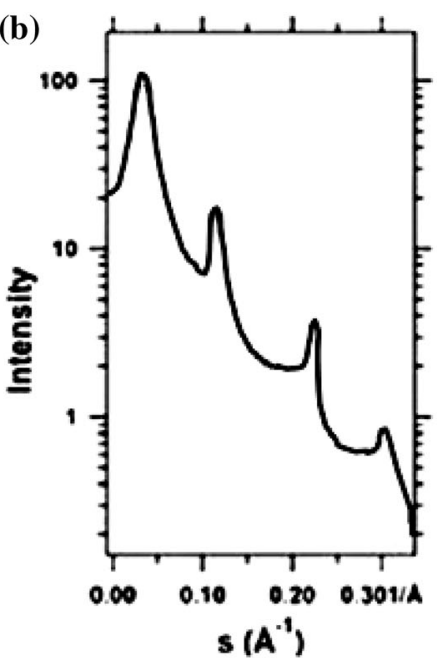

In melt growth systems of homopolymers, population of non-ideal structures was high in comparison to solution growth systems from which we observed pyramids with hexagonal bases. As a fact, the overall principle of effect of crystallization temperature on crystal thickness was not satisfied for non-ideal crystals while lateral size of such structures was highly compatible with that of ideal and monolayer single crystals (with error percentage below $5 \%$ ). Likewise, in dilute solution systems prepared with amyl acetate, the pyramids had square bases. In some cases, the conic crystals were detectable as well. Some offcentral pyramids and cones were recognized in which the upper layer had deviation from bottom layers. Figure $7 \mathrm{a}$ depicts TEM images of crystals in question. In our work, the lens-shaped crystals were also observed for the homo$\mathrm{PEG}_{5000}$. The lens-shaped crystals were previously reported for PS- $b$-PEO by Zheng and co-authors [55].

The effect of self-seeding temperature on single crystal lateral size was investigated in the frame of several experiments. For solution-grown single crystals of homo$\mathrm{PEG}_{5000}$ (in amyl acetate) when self-seeding temperature changed from 39 to $41{ }^{\circ} \mathrm{C}$, the lateral size varied from 4.38 to $6.54 \mu \mathrm{m}$. This indicated that proportional to elevation of self-seeding temperature, the lateral size of single crystals increased while their population in the system decreased. More details are reported elsewhere [56]. The crystallization temperature had the same effect on the thickness of developed single crystals.

\section{Homopolymer/block copolymer single-co-crystals}

Before focusing on details, we are supposed to bring some notions into consideration. A random single-co-crystal is a uniform crystalline structure having two or more crystallizable constituents. The surface morphology of these

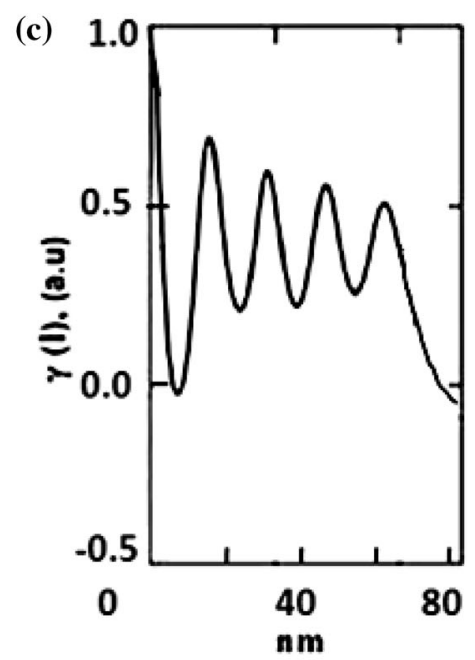

Fig. 6 2D SAXS pattern (a), reduced scattering curve (b) and 1D correlation function (c) 
Fig. 7 TEM images of offcentral conic crystal in solution growth system (up) and pyramidal crystal in melt growth system (down) of homo$\mathrm{PEG}_{5000}$; the scale bar is $3 \mu \mathrm{m}$ for solution state and $11 \mu \mathrm{m}$ for melt state (a); AFM height image of $\mathrm{PEG}_{5000}-b-\mathrm{PS}_{14800} /$ $\mathrm{PEG}_{5000}$ random single-cocrystals grown from amyl acetate at $T_{\mathrm{c}}=28{ }^{\circ} \mathrm{C}$ showing the uniformity in size and shape (b); STEM image of $\mathrm{PEG}_{5000^{-}} b$ $\mathrm{PMMA}_{13100} / \mathrm{PEG}_{5000}$ random single-co-crystals grown from amyl acetate at $T_{\mathrm{c}}=23{ }^{\circ} \mathrm{C}(\mathbf{c})$; the weight ratio of $\mathrm{PEG}_{5000^{-}} b$ $\mathrm{PS}_{14800} / \mathrm{PEG}_{5000}$ and $\mathrm{PEG}_{5000^{-}}$ $b$-PMMA $13100 / \mathrm{PEG}_{5000}$ was $50 / 50 \mathrm{wt} / \mathrm{wt}$ for cocrystallization (a)

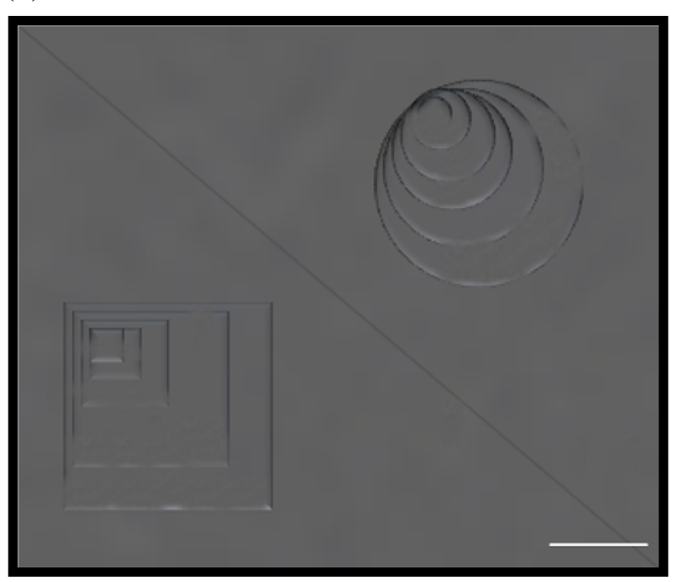

(b)

(c)

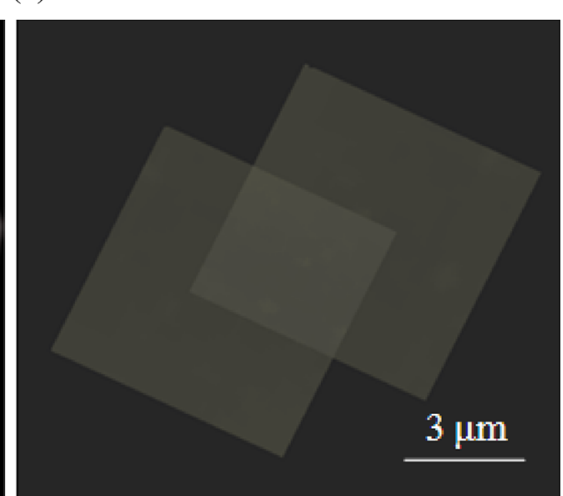

single crystals resembled homo-brush single crystals. Figure $7 \mathrm{~b}$, c depicts AFM height images of $\mathrm{PEG}_{5000}-b$ $\mathrm{PS}_{14800} / \mathrm{PEG}_{5000}$ random single-co-crystals grown at $T_{\mathrm{c}}=28^{\circ} \mathrm{C}$ and scanning transmission electron microscopy (STEM) image of $\mathrm{PEG}_{5000}-b-\mathrm{PMMA}_{13100} / \mathrm{PEG}_{5000}$ random single-co-crystals grown at $T_{\mathrm{c}}=23{ }^{\circ} \mathrm{C}$, respectively.

In the current paper, two approaches were presented for verification of random single-co-crystals. First, the total thickness obtained by AFM was higher for random cocrystals in comparison to corresponding homo-brush single crystals. The height profiles of the three sorts of single crystals crystallized at $T_{\mathrm{c}}=23,28$ and $32{ }^{\circ} \mathrm{C}$ in dilute solution of amyl acetate including homo-PEG ${ }_{5000}(10.33$, 11.09 and $11.55 \mathrm{~nm})$, random co-crystal of $\mathrm{PEG}_{5000}-b$ $\mathrm{PS}_{4600} / \mathrm{PEG}_{5000}(16.12,17.19$ and $18.61 \mathrm{~nm})$ and homobrush of $\mathrm{PEG}_{5000}-b-\mathrm{PS}_{4600}(13.96,15.12$ and $16.65 \mathrm{~nm})$ proved this claim. The mentioned trend was also detected in PMMA-based systems. The total thickness of single crystals grown at the same temperatures for homo$\mathrm{PEG}_{5000}$, random co-crystal of $\mathrm{PEG}_{5000}-b-\mathrm{PMMA}_{13100} /$ $\mathrm{PEG}_{5000}$, and homo-brush of $\mathrm{PEG}_{5000}-b$-PMMA 13100 were $10.33,15.52$ and $11.33 \mathrm{~nm}$, respectively. Irrespective of crystallization temperature and the sort of amorphous block, via increasing the amorphous block molecular weight, due to elevation of demanded coverage surface area and thus a bigger number of folds of the PEG crystal, the osmotic pressure on the substrate increased, thereby its thickness decreased. In addition, for all samples of the same group, through elevating the crystallization temperature, the increase of fold-length was a consequence of the system tendency towards the lowest state of free energy, which belonged to the fully extended chain crystals [18, 54].

Second, comparing TEM electron diffraction (ED) patterns of homo-PEG and homo-brush single crystals, one could behold that the central sphere of homo-brush single crystal is smaller than that of homopolymer crystal (Fig. 8). It could be related to higher order of homopolymer single crystals which did not have any disturbing amorphous brushes in their structure. Similarly, at the same growth condition, the size of central sphere for random cocrystals was greater in comparison with corresponding homo-brush single crystals, whereas it was smaller than that of respective homopolymer single crystals (Fig. 8). Due to presence of homo-PEG chains which did not have any amorphous blocks in random single-co-crystal structure, its ordering was higher than that of corresponding 
(a)

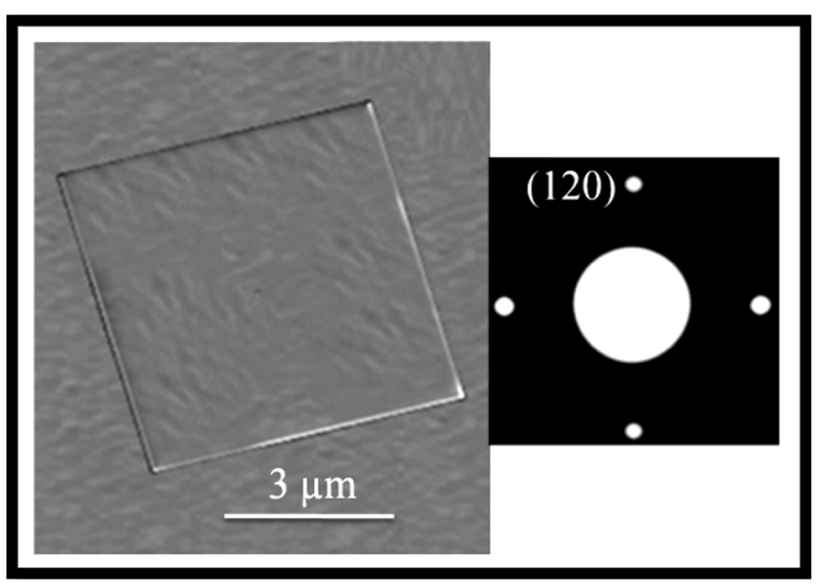

(b)

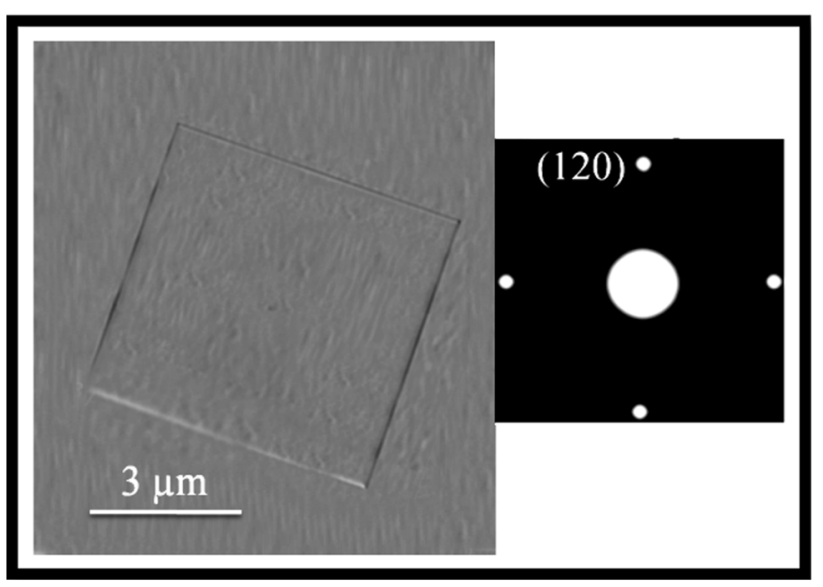

(c)

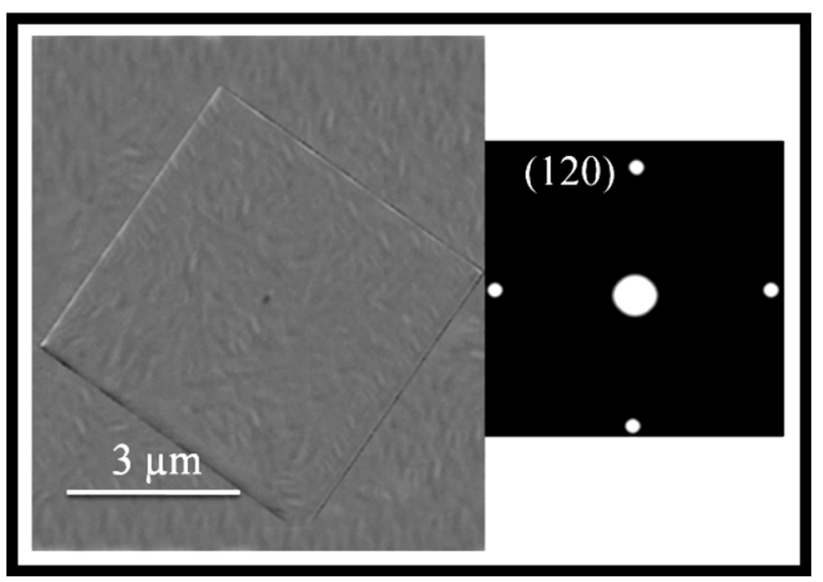

Fig. 8 TEM bright images accompanied by the corresponding SAED patterns of the cubic single crystals grown in amyl acetate at $T_{\mathrm{c}}=23{ }^{\circ} \mathrm{C}$; homo- $\mathrm{PEG}_{5000}$ (a); random co-crystal of $\mathrm{PEG}_{5000^{-}-b}$ $\mathrm{PS}_{10000} / \mathrm{PEG}_{5000}$ (b); homo-brush of $\mathrm{PEG}_{5000}-b-\mathrm{PS}_{10000}(\mathbf{c})$

homo-brush single crystal. Hence, the central spot of random single-co-crystal was bigger than that of homo-brush one. On the other side, the structural order of homopolymer single crystals was in a high level in comparison to the random co-crystals. Therefore, the mentioned spot was smaller for the latter ones. TEM bright images and ED patterns for grown single crystals in amyl acetate at $T_{\mathrm{c}}=23{ }^{\circ} \mathrm{C}$ consisting homo- $\mathrm{PEG}_{5000}$, random single-cocrystal of $\mathrm{PEG}_{5000}-b-\mathrm{PS}_{10000} / \mathrm{PEG}_{5000}$ and homo-brush of $\mathrm{PEG}_{5000}-b-\mathrm{PS}_{10000}$ are depicted in Fig. $8 \mathrm{a}-\mathrm{c}$, respectively. The ED patterns of all samples possessed four spots entitled (120) around the central core, representing four dominant fronts filled with the polymer chains. These major fronts constituted four sides of square of ideal and monolayer single crystal. This was in accordance with those that have been reported for homo-PEG and copolymer single crystals having PEG as crystalline substrate up to now [19, 42, 57, 58].

Generally, the determinative parameters on the thickness of single crystal substrate were the molecular weights of crystalline and amorphous blocks as well as the crystallization temperature. The fourth effective parameter that we introduced was disapproaching of tethered chains on the substrate. In conclusion, the relation applied for the grafting density of conventional homo-brush single crystals (Eq. 2) [55] was not more usable for the random single-cocrystals.

$\sigma=\frac{N_{0} \rho_{\mathrm{PEG}} d_{\mathrm{PEG}}}{2 M_{n}^{\mathrm{PEG}}}$

where $\sigma, N_{0}, \rho^{\mathrm{PEG}}, d_{\mathrm{PEG}}, M_{n}^{\mathrm{PEG}}$ stood for the tethering density, the Avogadro number $\left(6.022 \times 10^{23} \mathrm{~mol}^{-1}\right)$, crystalline PEG density (is equal to $1.239 \mathrm{~g} / \mathrm{cm}^{3}$ at room temperature) [59], PEG substrate thickness (Eq. 3) $[18,55]$, and the molecular weight of PEG $\left(=5000 \mathrm{~g} / \mathrm{cm}^{3}\right)$, respectively.

Equation (2) was only applicable for the systems, in which all contributing chains in the single crystal structure had the amorphous blocks. On the other hand, we did not know the accurate percentage of homo-PEG chains in random structure and the heterogeneity of their presence in different parts of single crystal structure as well. So, we were not capable of introducing a comprehensive relation with more scrutiny for grafting density of random singleco-crystal. The higher percentage of homo-PEG chains were included in the single crystal structure, the higher disapproach of tethered chains occurred on the substrate surface. Moreover, with entering the homo-PEG chains in the random structure, the tethered chains on the substrate disapproached. Therefore, the repulsive interaction between the brushes decreases and, consequently, each chain tended to reach more coily conformation. It in turn may cause the amorphous tethered brushes to decrease their height.

Despite considering explanations presented above, if we use the same equation applied for conventional homobrush single crystals (Eq. 3) to determine the thickness of 


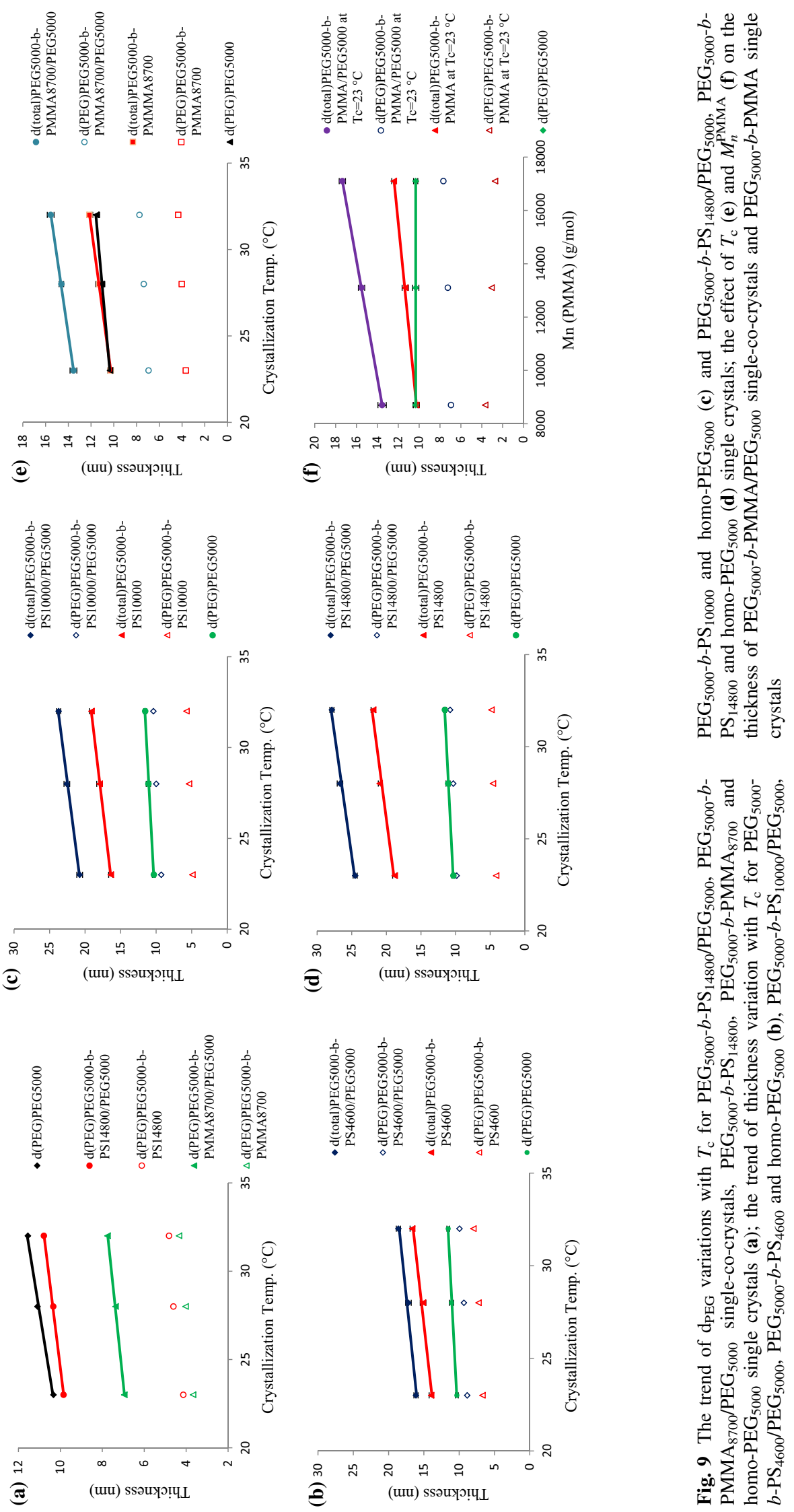


crystalline substrate $\left(d_{\mathrm{CRYST}}\right)$, and subtract it from total thickness $\left(d^{\text {total }}\right)$ obtained from AFM to gain the amorphous brushes height $\left(d_{\mathrm{AMORPH}}\right)$ for random single-co-crystals (in comparison with respective homo-brush ones), we see that $d^{\mathrm{AMORPH}}$ has risen instead of decreasing.

$d_{C R Y S T}=d^{\text {total }} \times \frac{M_{n}^{C R Y S T} / \rho_{C R Y S T}}{M_{n}^{C R Y S T} / \rho_{C R Y S T}+M_{n}^{A M} / \rho_{A M}}$

For the $\mathrm{PEG}_{5000}-b-\mathrm{PS}_{4600} / \mathrm{PEG}_{5000}$ at $T_{\mathrm{c}}=23{ }^{\circ} \mathrm{C}$, by subtracting $2 d_{\mathrm{AMORPH}} \quad$ of $\quad \mathrm{PEG}_{5000}-b-\mathrm{PS}_{4600} \quad(=2 \times$ $3.63 \mathrm{~nm})$ from $d^{\text {total }}$ of $\mathrm{PEG}_{5000}-b-\mathrm{PS}_{4600} / \mathrm{PEG}_{5000}$ $(=16.12 \mathrm{~nm})$, we could reach the corresponding thickness of random single-co-crystal $(8.86 \mathrm{~nm})$. This value was much closer to the respective thickness of homo- PEG $_{5000}$ single crystal $(=10.33 \mathrm{~nm})$ in comparison with the substrate thickness of corresponding homo-brush $\left(\mathrm{PEG}_{5000}-b\right.$ $\left.\mathrm{PS}_{4600}\right)$ single crystal $(=6.70 \mathrm{~nm})$ at the same condition. Comparing these data may help us conclude that in $\mathrm{PEG}_{5000}-b-\mathrm{PS}_{4600}$, the steric repulsive hindrance has been high enough to hamper the formation of thicker crystal, and the cooperation of homo-PEG chains has been very effective to reduce the osmotic pressure, and cause the substrate to increase its thickness.

For $\mathrm{PEG}_{5000}-b-\mathrm{PMMA}_{8700} / \mathrm{PEG}_{5000}$ at $T_{\mathrm{c}}=23{ }^{\circ} \mathrm{C}$, by subtracting $2 d_{\mathrm{AMORPH}}$ of $\mathrm{PEG}_{5000}-b-\mathrm{PMMA}_{8700}$ homobrush single crystal $(2 \times 3.30 \mathrm{~nm})$ from $d^{\text {total }}$ of $\mathrm{PEG}_{5000^{-}}$ $b$-PMMA $8700 / \mathrm{PEG}_{5000}$ random co-crystal $(13.55 \mathrm{~nm})$, we could thus determine the corresponding crystalline substrate thickness for $\mathrm{PEG}_{5000}-b-\mathrm{PMMA}_{8700} / \mathrm{PEG}_{5000}$ (=6.95 nm). This obtained $d_{\text {CRYST }}$ was somewhat located in the middle of range of homo-brush single crystal thickness $\left(d_{\mathrm{PEG}}\right)$ and that of $\mathrm{PEG}_{5000}$ one $(3.67-10.33 \mathrm{~nm})$. With increase of the amorphous block molecular weight, the portion of homo-PEG chains in the crystal structure has been raised, and it could be attributed to higher tendency of system to attract the homopolymers to lift the respective osmotic pressure off the substrate surface. Via increasing the amorphous block molecular weight, the critical quorum demanded to lift the osmotic pressure off the substrate, and to heighten its thickness increased. The effective parameters on the hindrance of single crystal systems fell into the solvent quality, the amorphous block molecular weight, and the interaction between the tethered amorphous chains and substrate surface. In these systems, the most dominant parameter on the substrate thickness was interaction between brushes and substrate surface. The mentioned trend was satisfied at elevated crystallization temperature as well.

Comparing the substrate thickness of homo-brush and random single-co-crystal of $\mathrm{PEG}_{5000}-b-\mathrm{PS}_{14800}$ and $\mathrm{PEG}_{5000}-b-\mathrm{PS}_{14800} / \mathrm{PEG}_{5000}(4.14$ vs. $9.85 \mathrm{~nm})$ (the highest $M_{n}^{P S}$ ) with those of $\mathrm{PEG}_{5000}-b-\mathrm{PMMA}_{8700}$ and $\mathrm{PEG}_{5000}-b$ -
$\mathrm{PMMA}_{8700} / \mathrm{PEG}_{5000} \quad(3.67$ vs. $6.95 \mathrm{~nm}) \quad$ (the lowest $M_{n}^{P M M A}$ ) at $T_{\mathrm{c}}=23{ }^{\circ} \mathrm{C}, \quad d_{\mathrm{PEG}}$ in $\mathrm{PEG}_{5000}-b-\mathrm{PS}_{14800} /$ $\mathrm{PEG}_{5000}$ was much closer to $d_{\mathrm{PEG}}$ in homo- $\mathrm{PEG}_{5000}$ in comparison to $\mathrm{PEG}_{5000}-b$ - $\mathrm{PMMA}_{8700} / \mathrm{PEG}_{5000}$. Hence, the attractive interaction between PMMA brushes and substrate surface had the most dominant effect on the substrate thickness, and even in the presence of homo-PEG chins it did not allow the substrate to increase its thickness. Different parts of Fig. 9 show the above-mentioned trends.

As a fact, via enhancement of amorphous blocks' molecular weight, especially for the PS, $d_{\mathrm{PEG}}$ of random single-co-crystal approached the respective thickness of homo-PEG single crystal grown at the same condition; because by increasing the length of amorphous brushes, the steric repulsion exerted between them increased and, consequently, the presence of homo-PEG chains (after reaching to the critical level) was capable of highly lifting the osmotic pressure off the substrate surface. So, difference between random co-crystal thickness and that of corresponding homo-PEG single crystal diminished. On the other hand, the critical quorum for increase of substrate thickness was higher in samples having longer amorphous chains. That is why to alter $\mathrm{d}_{\mathrm{PEG}}$, a larger number of homoPEG chains should be included into the random single-cocrystal structure. At $T_{\mathrm{c}}=23{ }^{\circ} \mathrm{C}$ for $\mathrm{PEG}_{5000}-b-\mathrm{PS}_{4600} /$ $\mathrm{PEG}_{5000}, \quad \mathrm{PEG}_{5000}-b-\mathrm{PS}_{10000} / \mathrm{PEG}_{5000}$ and $\mathrm{PEG}_{5000}-b$ $\mathrm{PS}_{14800} / \mathrm{PEG}_{5000}$ random co-crystals, $\mathrm{d}_{\mathrm{PEG}}$ ranged from 8.86 to $9.28 \mathrm{~nm}$ and, subsequently, to $9.85 \mathrm{~nm}$, respectively. By increasing the $M_{n}^{P S}$ from 4600 to $14800 \mathrm{~g} / \mathrm{mol}$, $\mathrm{d}_{\mathrm{PEG}}$ of random single-co-crystals reached $d_{\mathrm{PEG}}$ of homo$\mathrm{PEG}_{5000}$. The $d_{\mathrm{PEG}} \mathrm{S}$ of homo-brush single crystals decreased and disapproached from $d_{\mathrm{PEG}}$ of homo-PEG ${ }_{5000}$. Different parts of Fig. 9 show the above-mentioned trends.

\section{Conclusions}

The fibrillar P3HT single crystals from dilute solutions in toluene, xylene, and anisole $(0.01 \mathrm{wt} \%)$, the rectangular PEG single crystals from dilute solutions in amyl acetate, and the hexagonal PEG single crystals from the molten polymer thin films were prepared by means of the selfseeding technique. Furthermore, by co-crystallization the density of grafted chains on the substrate decreased without altering the molecular weights and crystallization temperatures. The total thickness of random single-co-crystals was higher than that of the corresponding homo-brush single crystals, and it was employed to verify the random structures. The 2D SAXS patterns demonstrated a good ordering in the arrangement of single crystals within stacked mats, and 1D correlation function showed that the samples had ideal lamellar morphologies. 
Open Access This article is distributed under the terms of the Creative Commons Attribution 4.0 International License (http://crea tivecommons.org/licenses/by/4.0/), which permits unrestricted use, distribution, and reproduction in any medium, provided you give appropriate credit to the original author(s) and the source, provide a link to the Creative Commons license, and indicate if changes were made.

\section{References}

1. Lotz, B., Kovacs, A.: Propriétés des copolymères biséquencés polyoxyéthylène-polystyrène, I. Préparation, composition et étude microscopique des monocristaux. Colloid Polym. Sci. 209, 97-114 (1966)

2. Baltá Calleja, F.J., Keller, A.: On the relation between long spacings, molecular length, and orientation in long chain compounds with reference to the possibility of chain folding. Part I. Oligomeric amides. J. Polym. Sci. A 2, 2151-2170 (1964)

3. Baltá Calleja, F.J., Hay, I.L., Keller, A.: Diffraction effects in single crystals and spherulites of poly (ethylene oxide). Colloid Polym. Sci. 209, 128-135 (1966)

4. Kovacs, A.J., Gonthier, A.: Crystallization and fusion of selfseeded polymers. Colloid Polym. Sci. 250, 530-552 (1972)

5. Kovacs, A.J., Gonthier, A., Straupe, C.: Isothermal growth, thickening, and melting of poly (ethylene oxide) single crystals in the bulk. J. Polym. Sci., Polym. Symposia 50, 283-325 (1975)

6. Kovacs, A.J., Straupe, C., Gonthier, A.: Isothermal growth, thickening, and melting of polyethylene oxide) single crystals in the bulk. II. J. Polym. Sci., Polym. Symposia 59, 31-54 (1977)

7. Lovinger, A.J., Lau, C.M., Gryte, C.C.: Microstructure of directionally solidified poly (ethylene oxide). Polymer 17, 581-586 (1976)

8. Cheng, S.Z.D., Bu, H.S., Wunderlich, B.: Double lamellae of low-molecular-mass fractions of poly (ethylene oxide) crystallized from the melt. Polymer 29, 579-583 (1988)

9. Snétivy, D., Vancso, G.J.: Atomic force microscopy of polymer crystals: 1 . Chain fold domains in poly (ethylene oxide) lamellae. Polymer 33, 432-433 (1992)

10. Hsiao, M.S., Zheng, J.X., Leng, S., Van Horn, R.M., Quirk, R.P., Thomas, E.L., Chen, H.L., Hsiao, B.S., Rong, L., Lotz, B., Cheng, S.Z.D.: Crystal orientation change and its origin in onedimensional nanoconfinement constructed by polystyrene-blockpoly(ethylene oxide) single crystal mats. Macromolecules 41, 8114-8123 (2008)

11. Abbaspoor, S., Abbasi, F., Agbolaghi, S.: Effects of various polymer brushes on the crystallization of poly(ethylene glycol) in poly(ethylene glycol)- $b$-polystyrene and poly(ethylene glycol)- $b$ poly(methyl methacrylate) single crystals. J. Polym. Res. 21(493), 1-8 (2014)

12. Agbolaghi, S., Abbaspoor, S., Abbasi, F.: Detection of polymer brushes developed via single crystal growth. Int. J. Nanosci. Nanotechnol. 12, 79-90 (2016)

13. Agbolaghi, S., Abbaspoor, S., Abbasi, F.: Synthesis of polymer nano-brushes by self-seeding method and study of various morphologies by AFM. Int. Nano. Lett. 6, 11-19 (2016)

14. Lin, E.K., Gast, A.P.: Semicrystalline diblock copolymer platelets in dilute solution. Macromolecules 29, 4432-4441 (1996)

15. Motomatsu, M., Niej, H.Y., Mizutani, W., Tokumoto, H.: Surface morphology study of poly(ethylene oxide) crystals by scanning force microscopy. Polymer 37, 183-185 (1996)

16. Li, B., Wang, B.B., Ferrier, R.C., Li, C.Y.: Programmable nanoparticle assembly via polymer single crystals. Macromolecules 42, 9394-9399 (2009)
17. Chen, X., Wang, W., Cheng, S., Dong, B., Li, C.Y.: Mimicking bone nanostructure by combining block copolymer self-assembly and 1D crystal nucleation. ACS Nano 7, 8251-8257 (2013)

18. Chen, W.Y., Zheng, J.X., Cheng, S.Z.D., Li, C.Y., Huang, P., Zhu, L., Xiong, H., Ge, Q., Guo, Y., Quirk, R.P., Lotz, B., Deng, L., Wu, C., Thomas, E.L.: Onset of tethered chain overcrowding. Phys. Rev. Lett. 93, 028301 (2004)

19. Chen, W.Y., Li, C.Y., Zheng, J.X., Huang, P., Zhu, L., Ge, Q., Quirk, R.P., Lotz, B., Deng, L., Wu, C., Thomas, E.L., Cheng, S.Z.D.: Chemically shielded poly(ethylene oxide) single crystal growth and construction of channel-wire arrays with chemical and geometric recognitions on a submicrometer scale. Macromolecules 37, 5292-5299 (2004)

20. Li, B., Li, L.Y., Wang, B.B., Li, C.Y.: Alternating patterns on single-walled carbon nanotubes. Nat. Nanotechnol. 4, 358-362 (2009)

21. Li, C.Y.: Polymer single crystal meets nanoparticles. Polym. Sci. Part B: Polym. Phys. 47, 2436-2440 (2009)

22. Dong, B., Miller, D.L., Li, C.Y.: Polymer single crystal as magnetically recoverable support for nanocatalysts. Phys. Chem. Lett. 3, 1346-1350 (2012)

23. Li, B., Li, C.Y.: Immobilizing $\mathrm{Au}$ nanoparticles with polymer single crystals, patterning and asymmetric functionalization. J. Am. Chem. Soc. 129, 12-13 (2007)

24. Wang, B.B., Li, B., Dong, B., Zhao, B., Li, C.Y.: Homo- and hetero-particle clusters formed by janus nanoparticles with bicompartment polymer brushes. Macromolecule 43, 9234-9238 (2010)

25. Fujiki, Y., Tokunaga, N., Shinkai, S., Sada, K.: Anisotropic decoration of gold nanoparticles onto specific crystal faces of organic single crystals. Angew. Chem. Int. Ed. 45, 4764-4767 (2006)

26. Minemawari, H., Yamada, T., Matsui, H., Tsutsumi, J., Haas, S., Chiba, R., Kumai, R., Hasegawa, T.: Inkjet printing of singlecrystal films. Nature 475, 364-367 (2011)

27. Kim, D.H., Han, J.T., Park, Y.D., Jang, Y., Cho, J.H., Hwang, M., Cho, K.: Single-crystal polythiophene microwires grown by selfassembly. Adv. Matt. 18, 719-723 (2006)

28. Jiang, X., Liu, X., Liao, Q., Wang, X., Yan, D.D., Huo, H., Li, L., Zhou, J.J.: Probing interfacial properties using a poly (ethylene oxide) single crystal. Soft Matter 10, 3238-3244 (2014)

29. Di Bonito, P., Petrone, L., Casini, G., Francolini, I., Ammendolia, M.G., Accardi, L., Piozzi, A., D'Ilario, L., Martinelli, A.: Aminofunctionalized poly (L-lactide) lamellar single crystals as a valuable substrate for delivery of hPV16-e7 tumor antigen in vaccine development. Int. J. Nanomed. 10, 3447-3458 (2015)

30. D'Ilario, L., Francolini, I., Martinelli, A., Piozzi, A.: Dipyridamole-loaded poly(L-lactide) single crystals as drug delivery systems. Macromol. Rapid Commun. 28, 1900-1904 (2007)

31. Petrone, L., Ammendolia, M.G., Cesolini, A., Caimi, S., Superti, F., Giorgi, C., Di Bonito, P.: Recombinant HPV16 E7 assembled into particles induces an immune response and specific tumour protection administered without adjuvant in an animal model. Transl. Med. 9, 1 (2011)

32. Dong, B., Zhou, T., Zhang, H., Li, C.Y.: Directed self-assembly of nanoparticles for nanomotors. ACS Nano 7, 5192-5198 (2013)

33. Liu, M., Liu, L., Gao, W., Su, M., Ge, Y., Shi, L., Zhang, H., Dong, B., Li, C.Y.: A micromotor based on polymer single crystals and nanoparticles: toward functional versatility. Nanoscale 6, 8601-8605 (2014)

34. Agbolaghi, S., Abbasi, F., Gheybi, H.: High efficient and stabilized photovoltaics via morphology manipulating in active layer by rod-coil block copolymers comprising different hydrophilic to hydrophobic dielectric blocks. Eur. Polym. J. 84, 465-480 (2016)

35. Rahimi, K., Botiz, I., Stingelin, N., Kayunkid, N., Sommer, M., Koch, F.P., Nguyen, H., Coulembier, O., Dubois, P., Brinkmann, 
M., Reiter, G.: Controllable processes for generating large single crystals of poly(3-hexylthiophene). Angew. Chem. Int. Ed. 51, $11131-11135$ (2012)

36. Hourani, W., Rahimi, K., Botiz, I., Koch, F.P.V., Reiter, G., Lienerth, P., Heiser, T., Bubendorff, J.L., Simon, L.: Anisotropic charge transport in large single crystals of $\pi$-conjugated organic molecules. Nanoscale 6, 4774-4780 (2014)

37. Dong, H., Jiang, S., Jiang, L., Liu, Y., Li, H., Hu, W., Wang, E., Yan, S., Wei, Z., Xu, W., Gong, X.: Nanowire crystals of a rigid rod conjugated polymer. J. Am. Chem. Soc. 131, 17315-17320 (2009)

38. Goto, H., Okamoto, Y., Yashima, E.: Solvent-induced chiroptical changes in supramolecular assemblies of an optically active, regioregular polythiophene. Macromolecules 35, 4590-4601 (2002)

39. Ma, Z., Geng, Y., Yan, D.: Extended-chain lamellar packing of poly (3-butylthiophene) in single crystals. Polymer 48, 31-34 (2007)

40. Kim, D.H., Park, Y.D., Jang, Y., Yang, H., Kim, Y.H., Han, J.I., Moon, D.G., Park, S., Chang, T., Chang, C., Joo, M., Ryu, C.Y., Cho, K.: Enhancement of field-effect mobility due to surfacemediated molecular ordering in regioregular polythiophene thin film transistors. Adv. Funct. Mater. 15, 77-82 (2005)

41. Kim, D.H., Park, Y.D., Jang, Y., Cho, K.: Solvent vapor-induced nanowire formation in poly(3-hexylthiophene) thin films. Macromol. Rapid Commun. 26, 834-839 (2005)

42. Agbolaghi, S., Abbasi, F., Jalili, K.: Nascent lateral habits of solution crystallization of poly (ethylene glycol)-block-polystyrene diblock copolymers. J. Polym. Res. 21(380), 1-11 (2014)

43. Abbaspoor, S., Abbasi, F., Agbolaghi, S.: A novel approach to prepare polymer mixed-brushes via single crystal surface patterning. RSC Adv. 4, 17071-17082 (2014)

44. Agbolaghi, S., Alizadeh-Osgouei, M., Abbaspoor, S., Abbasi, F.: Self-assembling nano mixed-brushes having co-continuous surface morphology by melt growing single crystals and comparison with solution patterned leopard-skin surface morphology. RSC Adv. 5, 1538-1548 (2015)

45. Agbolaghi, S., Abbasi, F., Abbaspoor, S., Alizadeh-Osgouei, M.: Self-designed surfaces via single-co-crystallization of homopolymer and diblock copolymers in various growth conditions. Eur. Polym. J. 66, 108-118 (2015)

46. Agbolaghi, S., Abbasi, F., Abbaspoor, S.: Epitaxial single crystal surface patterning and study of physical and chemical environmental effects on crystal growth. Colloid Polym. Sci. 292, 1375-1383 (2014)

47. Alizadeh-Osgouei, M., Agbolaghi, S., Abbaspoor, S., Abbasi, F.: A subtle insight into nano-convergence of substrate thickness in melt-grown single-co-crystals. Colloid Polym. Sci. 294, 869-878 (2016)

48. Nazari, M., Agbolaghi, S., Abbaspoor, S., Gheybi, H., Abbasi, F.: Arrangement of conductive rod nanobrushes via conductive-dielectric-conductive sandwiched single crystals of poly(ethylene glycol) and polyaniline block copolymers. Macromolecules $\mathbf{4 8}$, 8947-8957 (2016)

49. Agbolaghi, S., Nazari, M., Abbaspoor, S., Gheybi, H., Abbasi, F.: Micro/nano conductive-dielectric channels designed by poly (ethylene glycol) single crystals covered by polyaniline nanofibers. Polymer 92, 264-272 (2016)

50. Agbolaghi, S., Nazari, M., Abbaspoor, S., Gheybi, H., Abbasi, F.: Characterization of novel extremely extended regime in conductive rod-like polyaniline nanobrush-covered poly (ethylene glycol) single crystals. Eur. Polym. J. 82, 196-207 (2016)

51. Lohwasser, R.H., Thelakkat, M.: Toward perfect control of end groups and polydispersity in poly (3-hexylthiophene) via catalyst transfer polymerization. Macromolecules 44, 3388-3397 (2011)

52. Staton, W.O.: Newer methods of polymer characterization. In: Ke, B., (Ed.) Interscience, New York (1964)

53. Alexander, L.E.: X-ray diffraction methods in polymer science. Wiley-Interscience, New York (1969)

54. Hamie, H.: Morphology and thermal behavior of single crystals of polystyrene-poly(ethylene oxide) block copolymers. Ph.D. Dissertation, University of Haute Alsace (2010)

55. Zheng, J.X., Xiong, H., Chen, W.Y., Lee, K., Van Horn, R.M., Quirk, R.P., Lotz, B., Thomas, E.L., Shi, A.C., Cheng, S.Z.D.: Onsets of tethered chain overcrowding and highly stretched brush regime via crystalline-amorphous diblock copolymers. Macromolecules 39, 641-650 (2006)

56. Agbolaghi, S., Abbasi, F., Abbaspoor, S.: Preparation of polymer brushes via growth of single crystals of poly(ethylene glycol)block-polystyrene diblock copolymers synthesized by ATRP and studying the crystal lateral size and brush tethering density. Polym. Bull. 71, 3177-3196 (2014)

57. Lotz, B., Kovacs, A.J., Bassett, G.A., Keller, A.: Properties of copolymers composed of one poly-ethylene-oxide and one polystyrene block. Colloid Polym. Sci. 209, 115-128 (1966)

58. Xiong, H., Zheng, J.X., Van Horn, R.M., Jeong, K.U., Quirk, R.P., Lotz, B., Thomas, E.L., Brittain, W.J., Cheng, S.Z.D.: A new approach in the study of tethered diblock copolymer surface morphology and its tethering density dependence. Polymer $\mathbf{4 8}$, 3732-3738 (2007)

59. Wunderlich, B.: Macromolecular physics. Crystal structure, morphology, defects, vol. 1. Academic, New York (1973) 